\title{
PERCEPTION OF OCEAN WAVE DIRECTION BY SEA TURTLES
}

\author{
KENNETH J. LOHMANN, ANDREW W. SWARTZ AND CATHERINE M. F. LOHMANN \\ Department of Biology, University of North Carolina, Chapel Hill, NC 27599-3280, USA
}

Accepted 4 January 1995

\begin{abstract}
Summary
At the beginning of their offshore migration, hatchling sea turtles enter the ocean at night and establish a course away from land by swimming directly into oceanic waves. How turtles can detect wave direction while swimming under water in darkness, however, has not been explained.

Objects in a water column beneath the surface of the ocean describe a circular movement as waves pass above. In principle, swimming turtles might, therefore, detect wave direction by monitoring the sequence of accelerations they experience under water. To determine whether loggerhead (Caretta caretta L.) and green turtle (Chelonia mydas $\mathbf{L}$.) hatchlings can detect wave direction in this way,

movements that simulated waves approaching from their right sides attempted to turn right, whereas movements that simulated waves from the left elicited left-turning behavior. Movements simulating waves from directly in front of the turtles elicited little turning in either direction.

The results demonstrate that hatchling sea turtles can determine the propagation direction of ocean waves by monitoring the circular movements that occur as waves pass above. Although sea turtles are the first animals shown to be capable of detecting wave direction in this way, such an orientation mechanism may be widespread among other transoceanic migrants such as fish and cetaceans.
\end{abstract} we constructed a wave motion simulator to reproduce in air the circular movements that occur beneath small ocean waves. Hatchlings suspended in air and subjected to
Key words: orientation, waves, sea turtle, fish, cetaceans, marine, Caretta caretta, Chelonia mydas.

\section{Introduction}

During their offshore migration, sea turtle hatchlings swim away from their natal beaches and into the open ocean. Early in the migration, hatchlings maintain seaward headings by swimming directly into oceanic waves (Salmon and Lohmann, 1989; Lohmann et al. 1990; Lohmann and Lohmann, 1992). Because waves and swells move towards shore in shallow coastal areas, swimming into waves reliably leads hatchling turtles away from land and towards the open sea.

The mechanism turtles use to detect wave direction has remained a matter of speculation (Lohmann and Lohmann, 1992). Visual cues are not necessary for wave orientation because hatchlings can orient to waves in the absence of visible light (Lohmann et al. 1990; Wyneken et al. 1990). Moreover, turtles probably detect wave direction while under water because hatchlings surface only intermittently while migrating (Salmon and Wyneken, 1987). These considerations suggest that hatchlings detect wave propagation direction from beneath the surface of the ocean using a novel, nonvisual mechanism.

Objects in a water column beneath the surface of the ocean describe a circular path as waves pass above (Denny, 1988). Previous calculations (Lohmann and Lohmann, 1992) have indicated that accelerations that occur in typical near-surface wave orbits near the coast of Florida, USA, exceed by an order of magnitude the minimal $5 \mathrm{~cm} \mathrm{~s}^{-2}$ linear acceleration known to be detectable by a vertebrate inner ear (Lewis et al. 1985).

Given that the accelerations beneath typical waves are theoretically detectable by hatchlings, turtles may be able to determine their orientation relative to wave propagation direction by monitoring the sequence of accelerations they experience as waves pass above (Cook, 1984; Lohmann and Lohmann, 1992). For example, a turtle facing into approaching waves is accelerated upwards, then backwards, then downwards and finally forwards, with each wave cycle, whereas a turtle oriented in the direction of wave movement would be accelerated upwards, forwards, downwards, then backwards (Fig. 1). The turtle would need only to distinguish between these two sequences to differentiate orientation against and with wave propagation direction.

To determine whether hatchlings might detect wave direction in this way, we constructed a wave motion simulator to reproduce in air the circular movements that a turtle would normally encounter while swimming beneath small oceanic waves. Our results demonstrate that hatchling sea turtles are capable of determining the direction of ocean wave propagation by monitoring acceleration sequences. Such a mechanism for sensing wave direction may be widespread among diverse open-sea migrants. 


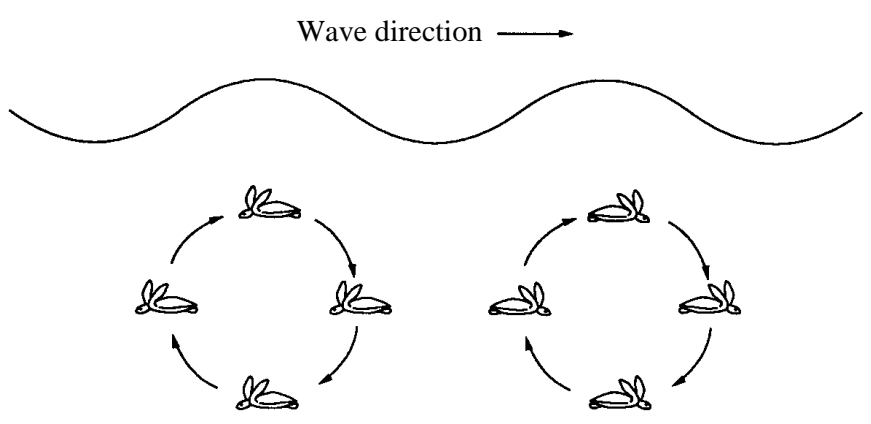

Fig. 1. The motion of a hatchling turtle swimming with and against the direction of wave propagation. For a hatchling oriented into waves (left), the sequence of accelerations during each wave cycle, beginning on the left, is upwards, backwards, downwards and forwards. A turtle swimming with the waves (right) is accelerated upwards, forwards, downwards and backwards.

\section{Materials and methods}

Animals

Loggerhead (Caretta caretta L.) and green turtle (Chelonia mydas L.) hatchlings were obtained from nests deposited on beaches in the vicinity of Boca Raton, Florida, USA. Nests were checked daily in the late afternoon. When a depression formed in the sand above the eggs (indicating that the eggs had hatched and that an emergence was imminent), we gently dug into the nest and removed approximately 20 hatchlings. The turtles were immediately placed into a Styrofoam cooler and transported to a laboratory. Each was subjected to a single 4 min trial on the wave simulator and then released on the natal beach later the same night.

\section{Activation of the swimming motor program in air}

As a hatchling sea turtle crawls on land, its left and right foreflippers move forward alternately. When the ventral surface of the hatchling fails to contact the substratum (normally indicating that the turtle has entered the sea), the swimming motor program is activated (Carr, 1963, 1981). Swimming movements are easily distinguished from crawling because both front flippers of a swimming turtle move forwards and backwards synchronously (Davenport et al. 1983). Hatchlings suspended in air will exhibit the swimming motor program for a period of hours as long as nothing contacts the ventral surfaces of their flippers (K. J. Lohmann, unpublished observations).

\section{Assessment of turning behavior}

Swimming turtles use their rear flippers as rudders for turning (Walker, 1971; Davenport et al. 1983). To turn left, for example, hatchlings stroke vigorously with the front flippers while extending the left rear flipper until it is nearly perpendicular to the sagittal plane of the animal (Walker, 1971) (Fig. 2). In contrast, right-turning is accomplished by extending the right rear flipper while holding in the left. Thus, extension of a rear flipper provides a simple, unambiguous indicator of attempted turning direction.

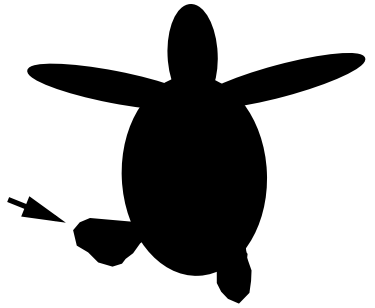

Left turning

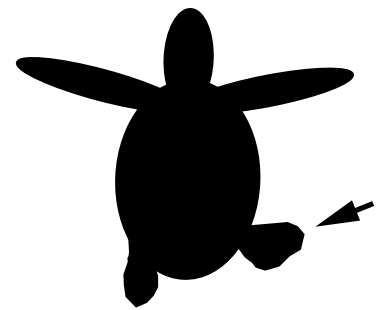

Right turning

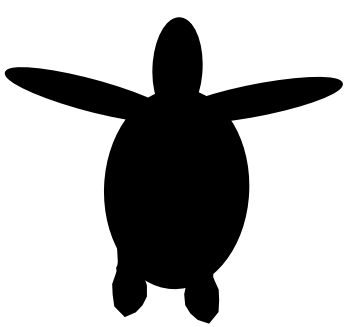

No turning
Fig. 2. Use of rear flippers as rudders by sea turtle hatchlings. To turn left while swimming, turtles paddle vigorously with their front flippers while extending the left rear flipper as a rudder. Hatchlings turning right extend the right rear flipper. Hatchlings swimming straight ahead keep both rear flippers close to the body.

\section{Wave simulator}

We constructed a wave simulator (Fig. 3) to reproduce in air the circular movements that occur beneath small oceanic waves. A small, variable-speed motor turned a belt, which in turn drove two identical acrylic arms coupled together by a second belt. As the arms rotated, they remained parallel to each other. Bearings connected a vertical post $(108 \mathrm{~cm}$ long) to the arms in such a way that the post remained vertical as the arms rotated. Thus, a hatchling attached to the bottom of the post was subjected to acceleration sequences simulating those occurring beneath waves.

As drawn, the hatchling in Fig. 3 would experience accelerations that simulate waves approaching from directly ahead (a sequence of upward, backward, downward and forward accelerations). To simulate waves approaching from other directions, the direction of the motor could be reversed (resulting in counterclockwise circles rather than clockwise circles), or the aluminum pivot could be rotated horizontally (so that the hatchling faced out of the page, for example, enabling acceleration sequences to simulate waves approaching from the turtle's left or right). Reversing the motor direction demonstrated that the turning responses of hatchlings were independent of noise or vibrations from the motor. Turtles subjected to simulated waves from the right or left, for example, were in identical positions relative to the motor; their treatments differed only in the sequence of accelerations they experienced. 


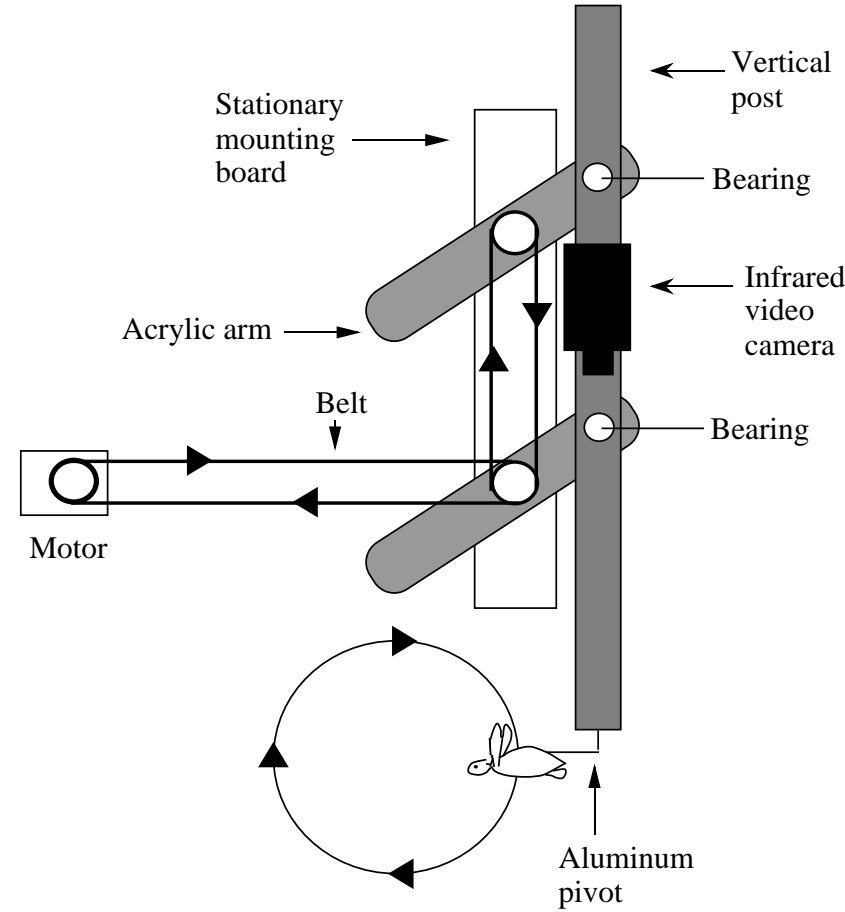

Fig. 3. Diagram of the wave motion simulator showing a hatchling experiencing simulated waves from directly ahead. See text for details.

\section{Calculation of accelerations}

To ensure that accelerations produced by the wave simulator were similar in magnitude to those that turtles normally experience beneath waves while migrating offshore, we calculated the horizontal and vertical accelerations that a hatchling would theoretically experience at an average swimming depth of $20 \mathrm{~cm}$ (Frick, 1976) beneath typical waves (amplitude $0.25 \mathrm{~m}$, period $5 \mathrm{~s}$ ) that occur near the east coast of Florida during the loggerhead hatching season (Hogben and Lumb, 1967). Our calculations relied on procedures described previously (Cook, 1984; Lohmann and Lohmann, 1992) and assumed that a stationary hatchling was facing into incoming waves.

The speed of the simulator motor was adjusted so that hatchlings were subjected to accelerations slightly smaller in magnitude than those calculated for the conditions described above. Accelerations on the simulator were determined from measured parameters (radius of circular movement $0.156 \mathrm{~m}$, period $5 \mathrm{~s}$ ). A comparison of the horizontal and vertical accelerations produced by the wave simulator and those theoretically encountered by migrating hatchlings swimming beneath typical Florida waves is shown in Fig. 4.

\section{Testing procedure}

Previous studies have suggested that hatchlings require several minutes in water before they attain the behavioral or physiological state in which they reliably orient to waves (Lohmann and Lohmann, 1992). Each hatchling was therefore placed into a bucket of sea water for at least $15 \mathrm{~min}$ before

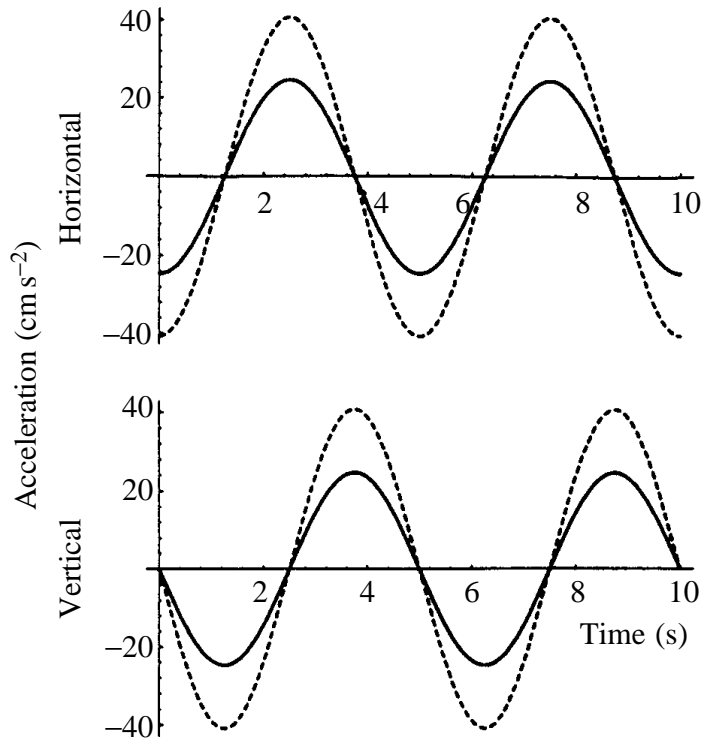

Fig. 4. Comparison of horizontal and vertical accelerations produced by the wave simulator (solid lines) and those theoretically encountered (dashed lines) by hatchlings oriented into typical waves near the east coast of Florida. The simulator produced accelerations slightly smaller in magnitude than those that would theoretically be experienced by a hatchling at an average swimming depth of $20 \mathrm{~cm}$ beneath typical waves $(0.25 \mathrm{~m}$ amplitude, period $5 \mathrm{~s})$ near the east coast of Florida during the turtle hatching season.

testing. Prior to each trial, a turtle was removed from the bucket, placed into a nylon/Lycra harness and attached to the wave simulator by means of a clip on the end of an aluminum pivot (Fig. 3). All observers then left the room, the room lights were turned off, and tests were conducted in darkness under infrared light.

Each trial began when the simulator was started using a remote switch. Each hatchling was allowed to adjust to the motion for $1 \mathrm{~min}$. Its response during the next $3 \mathrm{~min}$ was then videotaped with an infrared camera attached to the vertical post above the turtle (Fig. 3). In total, $8-10$ hatchlings (drawn from 2-4 different nests) were subjected to each treatment. The direction of simulated waves was altered after every two or three turtles.

In an initial experiment, groups of loggerhead hatchlings ( $N=10$ in each group) were subjected to acceleration sequences simulating waves approaching from one of four different directions (from the left, right, front and rear). In addition, three groups of green turtle hatchlings ( $N=10$ in each group) were tested with simulated waves approaching from the left, right and front.

In a second experiment with loggerhead hatchlings, the angle of wave approach was varied from $0^{\circ}$ (waves approaching from directly in front of the turtle) to $135^{\circ}$ (waves approaching $45^{\circ}$ clockwise from the turtle's tail). Prior to each test, the aluminum pivot to which hatchlings were attached (Fig. 3) was rotated to one of seven positions, so that simulated waves either approached the turtle from its front (angle of $0^{\circ}$ ), 


\section{K. J. Lohmann, A. W. Swartz and C. M. F. Lohmann}

or from its left side at angles of $22.5^{\circ}, 45^{\circ}, 67.5^{\circ}, 90^{\circ}, 112.5^{\circ}$ or $135^{\circ}$. Hatchlings were tested as before ( $N=8$ for each angle of simulated wave approach).

\section{Data analysis and statistics}

The tape of each 3 min trial was analyzed by measuring the total time (out of $180 \mathrm{~s}$ ) that a hatchling spent with (i) its left rear flipper extended, and (ii) with its right rear flipper extended. Independent analyses of the same videotaped sequences by different observers yielded consistent results (i.e. independent measures of left and right turning time never differed by more than $10 \mathrm{~s}$ and were usually within $3-5 \mathrm{~s}$ ).

The time that turtles spent turning left and right provided the basis for statistical analyses. Wilcoxon signed-ranks tests for paired comparisons were used to determine whether hatchlings under each simulated wave condition showed a significant preference for left or right turning.

\section{Results \\ Loggerhead hatchlings}

Results of initial experiments with loggerheads are summarized in Fig. 5. Turtles subjected to simulated waves from directly in front spent relatively little time attempting to turn in either direction (mean of $22 \mathrm{~s}$ for left turning and $22 \mathrm{~s}$ for right). Under these conditions, no significant preference existed for left or right turning (Wilcoxon signed-ranks test). In contrast, all 10 hatchlings subjected to simulated waves from the left spent more time turning left (mean 148s) than turning right (mean $4 \mathrm{~s}$ ); this turning preference was statistically significant (Wilcoxon test, $P<0.005$ ). All 10 hatchlings subjected to simulated waves from the right side spent more time attempting to turn right (mean 146s) than left (mean $8 \mathrm{~s})$; this preference was also significant $(P<0.005$, Wilcoxon test).

Whereas loggerheads subjected to simulated waves from the left or right consistently turned in a single direction, hatchlings subjected to simulated waves approaching from behind demonstrated extremely variable behavior. Some individuals $(N=4)$ spent most (at least $70 \%)$ of their $180 \mathrm{~s}$ attempting to turn right, whereas others $(N=2)$ showed similar strong preferences for turning left. The remaining turtles $(N=4)$ either alternated between turning left and turning right, or stopped attempting to turn after extending one rear flipper or the other for a short time.

\section{Green turtle hatchlings}

Results with green turtle hatchlings (Fig. 6) closely paralleled those obtained with loggerheads. Green turtles subjected to simulated waves from directly in front rarely attempted to turn and did not show a significant turning preference. In contrast, all 10 hatchlings subjected to simulated waves from the left spent more time turning left (mean $68 \mathrm{~s}$ ) than right (mean $3 \mathrm{~s})(P<0.005$, Wilcoxon test). All 10 green turtles subjected to simulated waves from the right spent more time attempting to turn right (mean $118 \mathrm{~s}$ ) than left (mean $1 \mathrm{~s}$ ) $(P<0.005$, Wilcoxon test). No attempt was made to subject green turtle hatchlings to simulated waves from behind.

\section{Simulated waves varying in approach angle}

In one experiment, loggerhead hatchlings were presented with simulated waves approaching from angles ranging from $0^{\circ}$ (head-on) to $135^{\circ}$ (i.e. $45^{\circ}$ clockwise from the tail). Hatchlings did not demonstrate a significant turning preference when waves approached from directly ahead. In all other cases, however, at least seven out of eight turtles turned into the simulated waves more than they turned in the opposite direction. Wilcoxon tests indicated that this turning preference was significant for each angle $\left(P=0.008\right.$ at $22.5^{\circ}$ and $45^{\circ}$; $P=0.004$ at $67.5^{\circ}, 90^{\circ}, 112.5^{\circ}$ and $\left.135^{\circ}\right)$.

Although turtles turned into simulated waves approaching from all angles other than $0^{\circ}$, the mean time spent turning
Fig. 5. Results from an initial experiment in which loggerhead hatchlings were subjected to acceleration sequences simulating waves approaching from one of four directions (from the front, left, right and rear). The filled bars represent the time out of $180 \mathrm{~s}$ that hatchlings spent turning left (time with the left rear flipper extended). The stippled bars indicate the time that hatchlings spent turning right (time with right rear flipper extended). Ten hatchlings from at least three different nests were tested in each position. Error bars indicate standard errors.

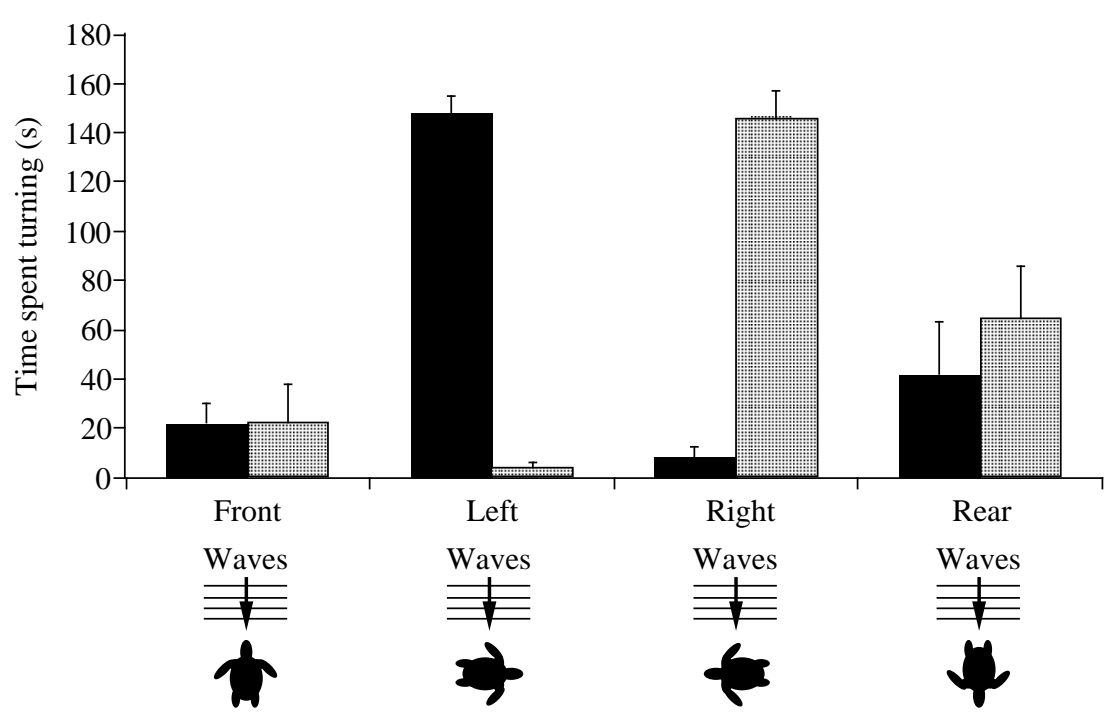

Direction of simulated waves 


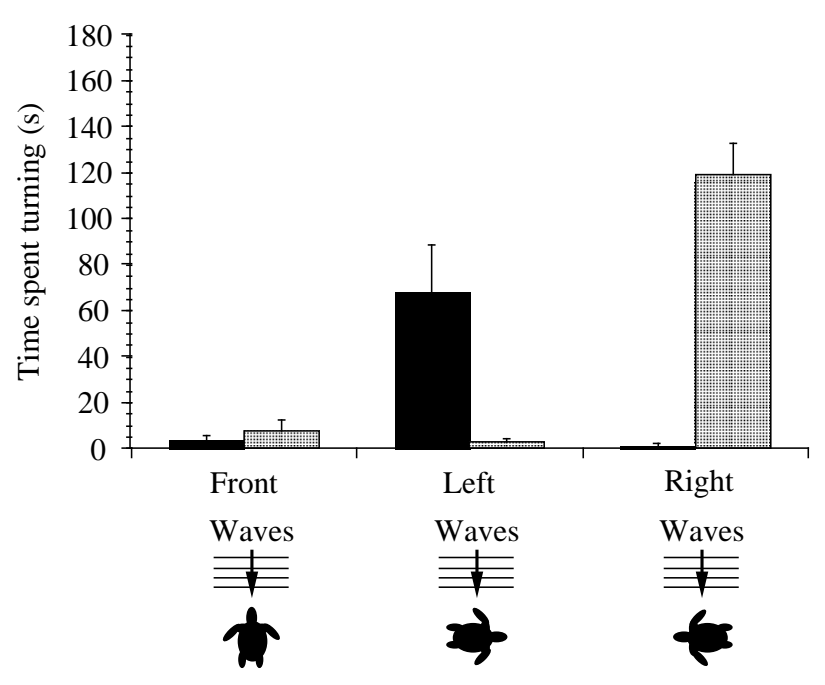

Direction of simulated waves

Fig. 6. Results obtained from green turtle hatchlings subjected to simulated waves approaching from one of three directions (front, left and right). Ten hatchlings from at least two different nests were tested in each position. Conventions as in Fig. 5.

increased progressively as the angle of wave approach increased from 0 to $90^{\circ}$ (Fig. 7). At the two angles greater than $90^{\circ}\left(112.5^{\circ}\right.$ and $\left.135^{\circ}\right)$, time spent turning into 'waves' remained high, but did not exceed that observed at $90^{\circ}$ (Fig. 7).

\section{Discussion}

Sea turtle hatchlings suspended in air and subjected to circular movements simulating waves approaching from their left or right sides consistently attempted to alter their courses by turning into the approaching 'waves'. When acceleration sequences simulated the conditions that hatchlings normally experience when oriented directly into waves, turtles spent relatively little time attempting to change course (Figs 5, 6). Thus, hatchling sea turtles have the ability to detect wave direction by monitoring the accelerations that occur as waves pass above.

The responses of loggerhead hatchlings to simulated waves approaching from directly behind (Fig. 5) were variable; some individuals turned left persistently, some turned right and others alternated between the two directions. If turtles are indeed motivated to turn in the direction that leads into the waves, then a left turn under these conditions would be as effective as a right turn in correcting the course. Thus, the results are consistent with the hypothesis that hatchlings determine their orientation relative to wave direction by monitoring accelerations and initiate corrective turning accordingly.

\section{Responses to simulated waves from different angles}

Hatchlings spent an increasing amount of time attempting to turn left as the angle of wave approach increased from 0 to $90^{\circ}$ (Fig. 7). Thus, as accelerations simulated progressively larger deviations from a course directly into waves, hatchlings spent progressively more time engaged in turning. These results imply that hatchlings can differentiate between headings almost directly into waves (e.g. the $22.5^{\circ}$ position) and headings at much larger angles to the waves (e.g. the $67.5^{\circ}$ and $90^{\circ}$ positions).

Turning time appeared to peak when waves approached from an angle of $90^{\circ}$ and remained high, but did not increase further, when the angle of wave approach was even larger. One possible interpretation is that hatchlings under the experimental conditions cannot distinguish between wave
Fig. 7. Results from experiments in which loggerhead hatchlings were exposed to simulated waves from one of seven directions. Conventions as in Fig. 5. Eight hatchlings drawn from at least two different nests were tested at each wave angle.

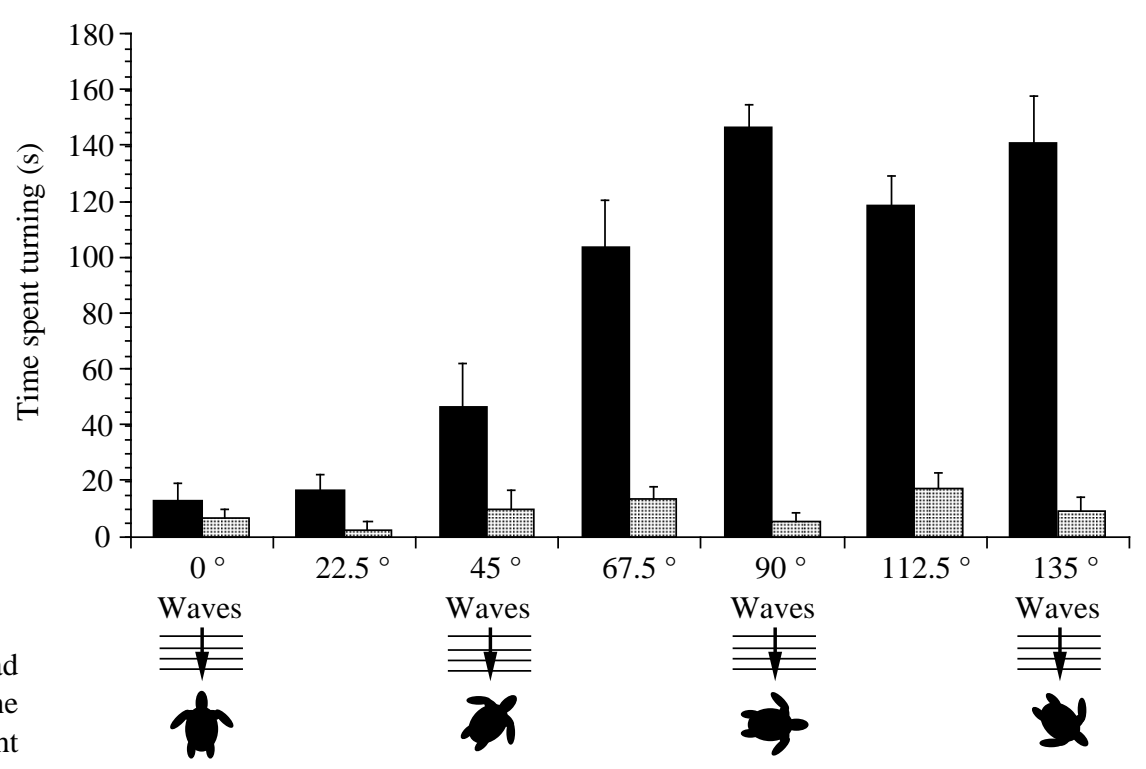

Direction of simulated waves 


\section{K. J. Lohmann, A. W. Swartz and C. M. F. Lohmann}

approach angles of $90^{\circ}, 112.5^{\circ}$ and $135^{\circ}$. An alternative possibility, however, is that hatchlings can indeed distinguish between these angles of approach, but that turning (or motivation to turn) had already reached a maximum level in the $90^{\circ}$ condition and thus could not be increased further.

\section{Response differences between loggerheads and green turtles}

To assess turning behavior in this study, we measured the amount of time a hatchling spent with its left or right rear flipper extended forward as a rudder (see Materials and methods). Although the turning responses of loggerhead and green turtle hatchlings were qualitatively identical (Figs 5, 6), loggerheads spent considerably more time attempting to turn when waves approached from the right (mean $146 \mathrm{~s}$ for loggerheads, $68 \mathrm{~s}$ for green turtles) or from the left (mean $148 \mathrm{~s}$ for loggerheads, $118 \mathrm{~s}$ for green turtles).

This apparent difference in behavior, however, may primarily reflect differences in how the two species normally achieve turning. The front flippers of green turtles are considerably larger and more powerful than those of loggerheads (Wyneken, 1990). Videotaped sequences from the wave simulator suggested that green turtle hatchlings initiated turning by extending their rear flippers for brief periods, but subsequently relied primarily on their front flippers in prolonged attempts to change course. Persistent attempts to turn left, for example, often consisted of a relatively brief extension of the left rear flipper, accompanied by longer periods in which the right front flipper was extended farther than the left during the swimming strokes.

We therefore suspect that rear flipper extension underestimates turning attempts by green turtles. Nevertheless, because relatively subtle differences in extension between the two front flippers are more difficult to assess than the unambiguous extension of a rear flipper, we used only the simpler measure of turning for this initial study.

\section{Orientation to waves during the natal migration}

In shallow water near shore, waves refract until they approach a beach directly (Bascom, 1980). Thus, swimming into waves after leaving a beach reliably leads hatchling turtles away from shore and towards the open sea (Lohmann and Lohmann, 1992).

In deeper water farther from land, waves no longer provide a reliable indicator of offshore direction. Evidence suggests, however, that hatchlings may orient into waves for only a short time after entering the sea. Hatchling loggerheads tracked from a Florida beach into the open ocean swam into waves initially, but soon established seaward courses that were seemingly independent of wave direction (Witherington, 1995). Thus, hatchlings may use one or more alternative sources of directional information to guide their movements after they have swum a short distance from land.

Recent laboratory experiments have demonstrated that loggerhead (Lohmann, 1991; Light et al. 1993; Lohmann and
Lohmann, 1994) and leatherback (Lohmann and Lohmann, 1993) turtles can orient by sensing the earth's magnetic field. One possibility is that magnetic orientation supplants or modulates wave orientation as hatchlings enter deeper water and waves become a less reliable indicator of offshore direction (Lohmann and Lohmann, 1994).

\section{Oceanic waves as an open-sea orientation cue}

Although waves in the open ocean do not reliably move towards land, they might still provide open-sea migrants with a consistent source of directional information. Because oceanic swells are generated by prevailing winds acting over large expanses of open sea, swell direction in many oceanic regions is relatively stable and largely independent of local weather conditions (Bascom, 1980). The directional constancy of swells has long been recognized; Polynesian navigators, for example, used swell direction as a directional cue (Lewis, 1978). Whether sea turtles continue to use waves as an orientation cue after completing the offshore migration has not been determined.

Oceanic swell direction might be especially useful to adult turtles, given that they must regularly migrate long distances between feeding and breeding grounds. Wave orientation has never been investigated in adult turtles, but there is no $a$ priori reason to suppose that adults cannot detect wave direction in the same way as hatchlings. Migrating adults presumably experience detectable accelerations at the depths where they normally swim; even $30 \mathrm{~m}$ below the surface, for example, the accelerations produced by typical oceanic swells theoretically exceed the threshold detectable by a vertebrate inner ear (Cook, 1984).

The ability to sense wave direction from acceleration sequences may therefore provide turtles with access to a reliable source of directional information that can be detected from considerable distances under water. Because acceleration sequences are unaffected by darkness or water clarity, turtles can presumably detect wave propagation direction under conditions in which visual features of the environment are difficult or impossible to perceive.

Although sea turtles are the first animals shown to be capable of detecting wave direction by monitoring the orbital movements that occur beneath waves, the same mechanism may be widespread among other marine animals. The ability to detect wave direction without surfacing seems particularly adaptive for other open-sea migrants such as fish and cetaceans.

We thank William Kier for assistance in designing the wave simulator, Sönke Johnsen for advice on wave analysis, Mike Salmon and Jeanette Wyneken for providing helpful suggestions and summer laboratory facilities at Florida Atlantic University, and Brent Jewell for his technical assistance. Sea turtle research was authorized under Florida DNR Special Permit TP-065 and was supported by NSF grant IBN-9120338. 


\section{References}

Bascom, W. (1980). Waves and Beaches. New York: Anchor Press Doubleday.

CARR, A. (1963). Orientation problems in the high seas: travel and terrestrial movements of marine turtles. In Bio-Telemetry (ed. L. E. Slater), pp. 179-193. New York: Macmillan Company.

CARr, A. (1981). Notes on the behavioral ecology of sea turtles. In Biology and Conservation of Sea Turtles (ed. K. A. Bjorndal), pp. 19-26. Washington, DC: Smithsonian Institution Press.

Cook, P. H. (1984). Directional information from surface swell: some possibilities. In Mechanisms of Migration in Fishes (ed. J. D. McLeave, G. P. Arnold, J. J. Dodson and W. H. Neill), pp. 79-101. New York: Plenum Press.

Davenport, J., Munks, S. A. And Oxford, P. J. (1983). A comparison of the swimming of marine and freshwater turtles. Proc. R. Soc. Lond. B 220, 447-475.

Denny, M. W. (1988). Biology and the Mechanics of the Wave-swept Environment. Princeton, NJ: Princeton University Press.

FrICK, J. (1976). Orientation and behaviour of hatchling green sea turtles (Chelonia mydas) in the sea. Anim. Behav. 24, 849-857.

Hogben, N. And Lumb, F. E. (1967). Ocean Wave Statistics. London: United Kingdom Ministry of Technology.

LewIS, D. (1978). The Voyaging Stars: Secrets of the Pacific Island Navigators. Sydney, Australia: Collins.

Lewis, E. R., Leverenz, E. L. AND BialeK, W. S. (1985). The Vertebrate Inner Ear. Boca Raton, FL: CRC Press, Inc.

Light, P., Salmon, M. And Lohmann, K. J. (1993). Geomagnetic orientation of loggerhead sea turtles: evidence for an inclination compass. J. exp. Biol. 182, 1-10.
LoHMAnN, K. J. (1991). Magnetic orientation by hatchling loggerhead sea turtles (Caretta caretta). J. exp. Biol. 155, 37-49.

Lohmann, K. J. And Lohmann, C. M. F. (1992). Orientation to oceanic waves by green turtle hatchlings. J. exp. Biol. 171, 1-13.

Lohmann, K. J. And Lohmann, C. M. F. (1993). A light-independent magnetic compass in the leatherback sea turtle. Biol. Bull. mar. biol. Lab., Woods Hole 185, 149-151.

Lohmann, K. J. And Lohmann, C. M. F. (1994). Acquisition of magnetic directional preference in hatchling loggerhead sea turtles. J. exp. Biol. 190, 1-8.

Lohmann, K. J., Salmon, M. And Wyneken, J. (1990). Functional autonomy of land and sea orientation systems in sea turtle hatchlings. Biol. Bull. mar. biol. Lab., Woods Hole 179, 214-218.

SALMON, M. AND LoHMANN, K. J. (1989). Orientation cues used by hatchling loggerhead sea turtles (Caretta caretta) during their offshore migration. Ethology 83, 215-228.

Salmon, M. AND WyneKen, J. (1987). Orientation and swimming behavior of hatchling loggerhead turtles (Caretta caretta L.) during their offshore migration. J. exp. mar. Biol. Ecol. 109, 137-153.

WALKER, W. F, JR (1971). Swimming in sea turtles of the family Cheloniidae. Copeia 2, 229-233.

Witherington, B. E. (1995). Observations of hatchling loggerhead turtles during the first few days of the lost year(s). In Proceedings of the Twelfth Annual Sea Turtle Symposium. NOAA Technical Memorandum. (in press).

WYNEKEN, J. (1990). Early swimming behavior in leatherback, loggerhead and green turtle hatchlings. Am. Zool. 30, 123A.

WyneKen, J., SALMON, M. AND Lohmann, K. J. (1990). Orientation by hatchling loggerhead sea turtles Caretta caretta L. in a wave tank. J. exp. mar. Biol. Ecol. 139, 43-50. 